\title{
Acute Medication Poisoning Causing Hospital Admissions in Childhood: a 3-Year Prospective Observational Single-Center Study
}

\author{
P. MATAlOVÁ ${ }^{1}$, M. PORUBA ${ }^{1}$, M. WAWRUCH ${ }^{2}$, P. ONDRA $^{3}$, K. URBÁNEK ${ }^{1}$ \\ ${ }^{1}$ Department of Pharmacology, Faculty of Medicine and Dentistry, Palacký University in Olomouc, \\ Czech Republic, ${ }^{2}$ Institute of Pharmacology and Clinical Pharmacology, Faculty of Medicine, \\ Comenius University, Bratislava, Slovakia, ${ }^{3}$ Department of Forensic Medicine and Medical Law, \\ Faculty of Medicine and Dentistry, Palacký University in Olomouc, Czech Republic
}

Received June 17, 2019

Accepted July 4, 2019

\section{Summary}

Although the risks of medication poisoning in children are often reported, there is a lack of studies addressing this issue. The majority of papers deal with a wide range of xenobiotics poisoning and, in particular, alcohol intoxications. All hospital admissions during three years were prospectively recorded. Patients younger than 19 years of age admitted for acute drug intoxications were further evaluated. A total of 15,069 children were admitted. Of them, 55 were hospitalized for acute medication poisoning. The condition was more common in girls ( $72.7 \%$ vs. $27.3 \%, \mathrm{p}<0.01$ ). Toddlers were the largest patient group (36.4\%). Non-steroidal anti-inflammatory drugs (NSAIDs) were the most frequently used agents, with ibuprofen being the leading drug ( $20 \%$ of all cases). The route of intoxication was almost exclusively oral. Solid drug forms were involved in $40(72.7 \%)$ cases. There was one fatal accidental poisoning. The highest occurrence of accidental drug intoxications was in the age group from one to three years. Attempted suicides were most frequent among adolescents. We are currently actively dealing with the issue. The cohort has been expanded to include a period of ten years and is being analyzed.

\section{Key words}

Medication poisoning • Drug intoxications • Children • Adolescents

\section{Corresponding author}

K. Urbánek, Department of Pharmacology, Faculty of Medicine and Dentistry, Palacký University in Olomouc, Hněvotínská 3, Olomouc, 775 15, Czech Republic. Fax: 00420585632552. E-mail: urbanek@fnol.cz

\section{Introduction}

Medication poisoning is one of the serious health-related risks in children. Prevention is of major importance, where simple precautions can prevent many serious but avoidable cases (Meyer et al. 2007). According to the data from the Toxicological Information Center (TIC) in Prague, Czech Republic, the largest proportion of all poisonings is caused by medications. The age of one to three years old carries the highest risk with a wide occurrence of noxae which can cause longlasting damage. Motor skills are already well developed in children of this age; however, they are still unable to rationally recognize dangerous situations. Drug intoxications (both by OTC and prescription medications) at this age are purely accidental, and any serious complications are rare (Rakovcová 2013, Pawłowicz et al. 2013, Sahin et al. 2011, Bates et al. 1997). In 2012, the TIC assessed 5,840 toddlers between the ages of one to three years, i.e. $72 \%$ of all queries in the age group up to 18 years. Certain number of sudden poisonings occurs even among younger children. In the first six months of age, these are mainly caused by parents. Other causes are accidental, for instance spillage of liquid drugs over the face, nose or mouth (Rakovcová 2013, Mühlendahl et al. 2003). By contrast, in adolescents, in the cases of attempted suicides, poisonings can either be fatal or cause long-lasting damage. In those cases, very toxic drugs are frequently used found by those individuals in home medicine cabinets; these are often medications taken by grandparents (Bentur et al. 2010). 
As for errors and accidents associated with misadministration of prescribed drugs, the victim commonly is a very young child. Those cases can involve situations of accidental swap of medications or of their inappropriate use and dosage. Another cause can be wrong understanding of the recommended dosage; also, it is not uncommon for different family members to give separate doses independently from one another (Rakovcová 2013).

A whole range of medicines can cause serious intoxications. A substantial risk is associated with cardiovascular medications, particularly calcium channel blockers, beta blockers, and digoxin. Other known causing agents are tricyclic antidepressants and carbamazepine, oral antidiabetics, antihistamines, and drugs containing iron ions. Cases in which parents unintentionally combine several anti-inflammatory agents containing paracetamol are also common. Moreover, parents often underestimate the toxic properties of paracetamol due to its presence in many easily available over-the-counter drugs (Mund et al. 2015, Peden 2008). Increasingly used slow release drug formulations which usually contain larger amounts of the active compound can lead to unpredictable clinical course of intoxication (Rakovcová 2013).

Although the risks of medication poisoning in children are often reported in the literature, there have not been many studies addressing this issue. The majority of papers published in this field deal with a wide range of xenobiotics poisoning and, in particular, alcohol intoxication. Studies describing the occurrence of medication poisonings leading to hospitalizations, however, are rather rare, limited to unintentional poisonings (Hoy et al. 1999) or specific type of medicinal products like opioids (Gaither et al. 2016). Although some earlier studies have brought interesting results, the spectrum of drugs used is changing quite rapidly. Therefore, we consider it useful to complement the study specifically addressing intoxications caused by medicinal products, in particular because of the identification of the risks of individual types of medicines.

\section{Aim of the study}

The aim of this study was to evaluate the prevalence, causes, and outcomes of medication poisonings leading to hospital admission in children over a three-year period in the University Hospital in Olomouc, Czech Republic.

\section{Ethics approval}

The study was approved by the Local Institutional Research Ethics Committee [No. 1236/04 S-IV].

\section{Methods}

All admissions to the Department of Pediatrics (DP) of the University Hospital Olomouc, Czech Republic, including surgical cases and hospitalizations for specialized diagnostic purposes were screened in the electronic Hospital Information System. The study period was from January 1, 2010 to December 31, 2012. All patients aged 18 years and younger possibly admitted because of acute pharmaceutical drug intoxications, both intentional and unintentional, were further evaluated. Patients who were admitted because of adverse drug reactions caused by usual therapeutic doses or because of intoxication by alcohol, "street" drugs, chemical compounds, poisonous plants, food or other noxious agents were excluded from the study.

The study was conducted following the guidelines of the Declaration of Helsinki. All data were processed anonymously.

Admissions were assessed in the hospital information system on a daily basis. The study team collected the following information from the case notes: age, sex, the substance and its formulation, source of the agent, causes of poisoning, presenting complaint and clinical symptoms on admission, the length of hospital stay, and information on patient's condition at discharge.

The results of toxicological analysis including detection of toxic agents in blood, urine and/or gastric content, and measurements of plasma levels of the substances were also evaluated. The following methods were used at the Department of Forensic Medicine and Medical Law for toxicology analysis: fluorescence polarization immunoassay (FPIA), thin layer chromatography (TLC), gas chromatography-mass spectrometry (GC-MS), gas chromatography with electron capture detector (GC-ECD), and highperformance liquid chromatography (HPLC).

Continuous data were expressed as mean \pm standard deviation, while categorical variables as frequency and percentage.

\section{Results}

Over the study period, a total of 15,069 children and adolescents were admitted to the DP. Of them, 55 were 
hospitalized for (suspected) acute medication intoxication, which accounts for $0.36 \%$ of all patient admissions to the DP. None of the intoxicated patients was admitted repeatedly during the study period for the same reason.

In general, poisoning was more common in girls than in boys $(72.7 \%$ vs. $27.3 \%, \mathrm{p}<0.01)$. Toddlers were the largest patient group $(36.4 \%)$, followed by schoolchildren $(27.3 \%)$, and adolescents (14.5\%). In the two oldest age groups (i.e. children $\geq 12$ years), girls prevailed significantly (Table 1$)$.

Table 1. Distribution of the patients hospitalized for acute drug intoxication according to the age and sex.

\begin{tabular}{lcccc}
\hline \multicolumn{1}{c}{ Age group } & Age & $\begin{array}{c}\text { Number of patients } \\
(\mathbf{\%})\end{array}$ & $\begin{array}{c}\text { Female } \\
\mathbf{( \% )}\end{array}$ & $\begin{array}{c}\text { Male } \\
(\mathbf{\%})\end{array}$ \\
\hline Newborns & $0-28 \mathrm{~d}$ & $0(0)$ & $0(0)$ & $0(0)$ \\
Infants & $29-364 \mathrm{~d}$ & $6(10.9)$ & $4(7.3)$ & $2(3.6)$ \\
Toddlers & $1-3 \mathrm{y}$ & $20(36.4)$ & $11(20)$ & $9(16.4)$ \\
Preschoolers & $3-6 \mathrm{y}$ & $4(7.3)$ & $4(7.3)$ & $0(0)$ \\
Early school age children & $6-11 \mathrm{y}$ & $2(3.6)$ & $0(0)$ & $2(3.6)$ \\
Schoolchildren & $11-15 \mathrm{y}$ & $15(27.3)$ & $8(14.5)$ & $2(3.6)$ \\
Adolescents & $15-19 \mathrm{y}$ & $8(14.5)$ & $\mathbf{4 0}(\mathbf{7 2 . 7})$ & $\mathbf{1 5}(0)$ \\
Total & $\mathbf{0 - 1 9} \mathbf{~ y ~}$ & $\mathbf{5 5 ( 1 0 0 )}$ & & \\
\hline
\end{tabular}

$\mathrm{d}-$ days of postnatal age, $\mathrm{y}-$ years.

Table 2. Drugs most frequently involved in children's intoxications in the study period.

\begin{tabular}{|c|c|c|c|c|}
\hline \multirow{2}{*}{ Active agent } & \multirow{2}{*}{ Drug formulation } & \multicolumn{3}{|c|}{ Number of cases } \\
\hline & & Unintentional & Intentional & Total \\
\hline \multirow[t]{3}{*}{ Paracetamol } & Tablets & - & 8 & 8 \\
\hline & Oral solution & - & - & - \\
\hline & Suppositories & - & - & - \\
\hline Ibuprofen & Tablets & 4 & 7 & 11 \\
\hline Dimetindene & Solution & 3 & - & 3 \\
\hline Gentian violet & Solution & 3 & - & 3 \\
\hline \multirow[t]{2}{*}{ Clonazepam } & Tablets & 1 & - & - \\
\hline & Solution & 1 & - & - \\
\hline Ascorbic acid & Tablets & - & 2 & - \\
\hline Zolpidem & Tablets & 2 & - & - \\
\hline Verapamil & Tablets & 1 & 1 & - \\
\hline
\end{tabular}

Analgesics were the most frequently used agents, with ibuprofen being the leading drug (20\% of all cases), followed by paracetamol (14.5\%). Gentian violet, dimetindene, clonazepam, ascorbic acid, zolpidem, and verapamil were also repeatedly reported as the cause of intoxication (Table 2). In individual cases, the following active agents were involved: levothyroxine, salicylic acid, levocetirizine, meloxicam, folic acid, moxastine teoclate, buprenorphine, dosulepin, atropine, bisulepin, tizanidine, bromazepam, alprazolam, citalopram, risperidone, melperon, betaxolol, codeine, tiapride, sertraline, tramadol, zolpidem, oxazepam, clonazepam, escitalopram, fluoxetine, aripiprazole, carvedilol, cholecalciferol, ferric oxide, phenoxymethylpenicillin, warfarin, perindopril, indapamid, trandolapril, propafenone, thiethylperazine, dextromethorfan, clenbuterol, zinc oxide, dutasteride, and oxymethazoline.

The route of intoxication was almost exclusively oral. Solid drug forms were involved in $40(72.7 \%)$ cases. The second most common form, liquids (which 
comprised oral solutions, solutions for external use, eye drops, and nasal drops), were ingested in $13(23.6 \%)$ cases. Transdermal therapeutic system (applied to the skin) and ointment were each responsible for one case of poisoning $(1.8 \%)$.

When analyzing the source of the pharmaceutical agent, the child was intoxicated by an agent that was indicated for someone else in 26 cases $(47.3 \%)$, whereas in 19 cases $(34.5 \%)$ it was by a medicinal product intended for their own use. In $18.2 \%$ of cases it was impossible to identify.

On admission, $40 \%$ of children were asymptomatic. In the remaining patients, the most frequent symptoms were neurological, such as malaise and somnolence, which were present in $27.3 \%$ of all patients, followed by gastrointestinal symptoms, such as nausea, vomiting, and abdominal pain, which were observed in $25.5 \%$ of children. More severe symptoms, such as tachycardia, restlessness, and excitation, occurred in four patients $(7.3 \%)$. During the study period, there was only one case of a comatose patient at admission. It was a toddler poisoned with a combination of cardiovascular medicines who eventually died.

We found $41.8 \%$ of intoxications to be intentional, while $58.2 \%$ were accidental and unintentional. The latter group comprised mainly of toddlers and preschoolers who found pharmaceutical agents while playing.

A suicide attempt as a cause of intoxication was detected in 18 patients $(32.7 \%)$, with girls representing the vast majority (17 cases). The remaining intentional intoxications were committed in order to draw attention, with no real intention to harm. Some of these girls had already been hospitalized for the same reason in the past. In our study, tablets were the dosage form chosen for a suicidal attempt. In ten cases, a single pharmaceutical agent was used. Seven children got intoxicated with a medicinal product originally indicated for them, whereas using a medication that was prescribed for someone else was registered in three cases. In the remaining eight cases, the source was not identified. None of the attempts resulted in death. Five patients were transferred to a psychiatric department.

The agents most frequently involved in suicidal attempts were analgesics, with paracetamol being the leading agent ( 8 cases), followed by ibuprofen ( 7 cases). Other frequent drug classes were antidepressants, with sertraline as the leading agent ( 3 cases), and cardiovascular medications of which betaxolol was chosen most often. Antihistamines, benzodiazepines, and antipsychotic medications were also involved repeatedly.

Toxicological tests were requested in 36 children (65.5\% of those admitted due to suspected acute drug intoxication), and in 30 of them, the active substance was qualitatively confirmed by TLC or GC-MS in urine and/or gastric content. In 13 patients, the agent was quantitatively determined in the plasma; in one patient, two different agents were detected (Table 3). The remainder of the patients (19) was hospitalized for a short-term observation.

The average duration of hospital stay was $2.37 \pm 2.52$ days. Most patients were discharged in a good general condition within $48 \mathrm{~h}$ (70.9\%). Five patients were transferred to the psychiatric department and one to another hospital. There was only one case of hospital stay longer than ten days. It was a toddler who ingested a combination of antiarrhythmics, a single tablet of propafenone, and a single tablet of verapamil, and who eventually died due to intoxication sequelae and multiple organ failure.

\section{Discussion}

During the period of study, a total of $0.36 \%$ of all child hospitalizations was caused by drug intoxication. The majority of previous research does not focus solely on medication poisonings, but also includes poisonings by alcohol, chemicals, fungi, detergents or carbon oxide. The most significant results were published in the United States in 2001. During a period of 11 years, the authors followed cases of hospitalization that were caused by drug poisoning among adolescents aged up to 19 years in the U.S. state of Washington. They identified 7,322 hospitalizations, which meant 45 cases in every 100,000 children a year. Medication poisonings accounted for $80 \%$ of all the cases (Gauvin et al. 2016). In 2006, another study assessed drug poisoning in children hospitalized in 17 Spanish hospitals. This study evaluated of a sample of 2,157 children in which drug poisonings accounted for $55 \%$ of all the cases (Mintegi et al. 2006). Also, in other studies published, medication poisoning was the main cause of all poisonings among children; however, one study found alcohol to be the main cause (in $50 \%$ of all the cases) in northeast Poland (Pawłowicz et al. 2013). Burghardt et al. (2013) proved that increasing adult drug prescriptions are strongly associated with rising pediatric exposures and poisonings, particularly for opioids and among children 0 to 5 years old. 
Table 3. Plasma levels of drugs determined by fluorescence polarization immunoassay and chromatographic methods in patients hospitalized in the Department of Pediatrics of the University Hospital Olomouc, Czech Republic, for acute drug intoxication.

\begin{tabular}{ccccc}
\hline Patient & Method & Agent & Concentration (mg/l) & Hours after ingestion \\
\hline 1 & FPIA & paracetamol & $70.5 ; 41$ & $3 ; 5.25$ \\
2 & FPIA & paracetamol & $65 ; 12.3$ & $5 ; 12.75$ \\
3 & FPIA & paracetamol & 25.6 & NA \\
4 & GC-ECD & alprazolam & 0.033 & \\
5 & GC-ECD & clonazepam & 0.05 & 17 \\
6 & FPIA & paracetamol & 44.9 & $1.25 ; 3.75 ; 21.75$ \\
7 & FPIA & paracetamol & $173.5 ; 91.7 ; 1.47$ & 5.75 \\
8 & FPIA & paracetamol & 23.69 & $4 ; 8.25 ; 16.5$ \\
9 & FPIA & paracetamol & $75 ; 27.6 ; 3.16$ & 5 \\
10 & FPIA & paracetamol & 12.3 & \\
11 & GC-MS & clonazepam & 0.14 & \\
12 & GC-MS & verapamil & 2.1 & \\
12 & HPLC & glibenclamide & 0.85 & \\
13 & GC-MS & verapamil & 0.03 & \\
\hline
\end{tabular}

FPIA - fluorescence polarization immunoassay, GC-ECD - gas chromatography with electron capture detector, GC-MS - gas chromatography-mass spectrometry, HPLC - high-performance liquid chromatography. More than one value in two patients was due to successive measurements of the agent during hospitalization. In patient 12 , levels of two different agents were determined.

It is necessary to point out that it is often not absolutely certain that children hospitalized due to drug poisoning had actually swallowed any drugs. An active agent was proven only in 30 of our cases $(54.5 \%)$ and significant concentrations were found only in 13 children $(23.6 \%)$. It is not unusual to encounter children who have been "playing" with drugs and the parent not being able to determine whether they have actually swallowed them. In such instances, those children are taken in for one-day observation.

In our study, $55 \%$ of children were older than six years of age. Other published studies focused only on younger children. For instance, in a study from 2011, the authors reported all cases of medication poisonings in children younger than 14 years of age during a period of three years and their subsequent hospitalizations. Among 330 intoxicated children, $72 \%$ were younger than five years of age (Akin et al. 2011). In another two studies, intoxications occurred in $64 \%$ of children younger than five years of age (Andiran and Sarikayalar 2004), or mostly in children younger than six (Ouédraogo et al. 2012). The reason for this difference is in the fact that we included patients up to the age of 19 years and have concentrated only on intoxications caused solely by medically used drugs. Among adolescents, the most frequent attempts of suicide are those involving drugs of abuse.

Medication intoxications occurred among children up to the age of 3 years in $47 \%$ of cases and in the age group over twelve years old in $42 \%$. In an older Canadian analysis of cases, $42 \%$ of children younger than three years old were most often hospitalized and $33 \%$ of those over the age of twelve (Lacroix et al. 1989). In the aforementioned Spanish study, medication intoxications accounted for $55 \%$ of all cases among children younger than four years of age in $67 \%$ of cases (Mintegi et al. 2006). Shotar (2005) focused purely on medication intoxications and in his study $90 \%$ of children who were hospitalized were younger than six years of age. The variations in findings can be attributed to varying methods of research, regional differences in medical care, and the varied extent of medical services. However, it is clear that sudden accidental drug intoxications occur between the ages of one and three. Suicidal attempts are the most common event among adolescents. It seems that these findings are valid worldwide, as suggested by the data from Peden (2008).

Our study found that $70.9 \%$ of cases of hospitalizations were shorter than two days. Furthermore, in other studies published, the average length of hospital stay was short; for instance, according to Sahin et al. (2011), $93 \%$ of children were discharged after $48 \mathrm{~h}$. 
Similarly to a study published in 2004 (Andiran and Sarikayalar 2004), we have found that intoxication most frequently occurred due to ingestion. At the time of hospitalization, $60 \%$ of our patients had the presumed symptoms. In the aforementioned study, only $29 \%$ of patients had symptoms (Mintegi et al. 2006) and in another one $34 \%$ of patients (Andiran and Sarikayalar 2004); however, these studies did not focus solely on intoxications by medicinal drugs.

Medications that caused the majority of intoxication cases were analgesics, namely paracetamol and ibuprofen, which are both readily available over the counter and kept in most households. When a parent does not follow the recommended dosage, the child can easily consume toxic amounts. Similarly, adolescents can easily access these drugs over the counter and abuse them in suicidal attempts.

In the above-mentioned American study, analgesics were the most frequent cause of drug poisonings, closely followed by antidepressants and psychotropic agents (Gauvin et al. 2001). Paracetamol was the leading cause in a study published in 2006 (Mintegi et al. 2006). However, in another study, antidepressants were the main cause, mainly tricyclic and tetracyclic ones, followed by analgesics, particularly paracetamol (Akin et al. 2011). In another study, medication intoxications occurred mainly due to tricyclic antidepressants (11.7\%), followed by methylphenidate (Sahin et al. 2011). Yet another study reported drug intoxications to be attributed to psychotropic compounds (56\%) (Shotar 2005).

Intended acts of self-poisoning occur most frequently among adolescents. In our study, they accounted for $42 \%$ cases. Suicidal attempts were confirmed in $33 \%$ of patients. In all the cases, the poisoning was caused by tablets. Girls were responsible for $94 \%$ of all suicide attempts, which is a number similar to that reported by Duramaz et al. (2015). In our research, $56 \%$ of suicidal attempts were caused by consuming a combination of medications and, in $44 \%$ of suicide attempts, only one drug was taken. Patients were most frequently attempting commit suicide by abusing analgesics (namely paracetamol and ibuprofen), due to easy access to these drugs. These are similar results to data from the TIC database which assessed suicidal attempts in children and adolescents. According to them, suicide is most frequently attempted by girls $(77 \%$ of cases), medication poisonings account for $98 \%$, and abuse of more than three drugs for $10 \%$. The drugs used were mainly NSAIDs and CNS drugs (Zakharov et al. 2013, Kizilyildiz et al. 2018).

In another recent study, suicidal attempts were most frequent among children over the age of ten years, caused mainly by either antidepressants or combinations of drugs. In $90 \%$ the child took just one drug with the aim to commit suicide; in $10 \%$ they took several drugs at a time (Akin et al. 2011). Also, in children older than ten years of age, girls were predominant (79\%) (Andiran and Sarikayalar 2004, Zakharov et al. 2013, Gummin et al. 2018).

Fortunately, the mortality caused by drug intoxication is not very high. In our sample, only one death was recorded, i.e. mortality rate of $1.8 \%$. It was a two-year-old boy brought unconscious to the hospital by his mother. During transport, his condition worsened due to spasms and gasping respiration. Subsequently, the boy was intubated and taken to the University Hospital in Olomouc. The declared cause of death was an accidental swallowing of one tablet of verapamil and one tablet of propafenone. The two agents were found in both his stomach content and urine. His blood contained $0.03 \mathrm{mg} / 1$ of verapamil. The boy died after two weeks in hospital without regaining consciousness. The available literature does not contain any case report of such a poisoning followed by death. The only recorded case presented an accident of a three-and-a-half-year-old child who took six tablets of Tarka ${ }^{\circledR}$ (i.e. a combination of verapamil and trandolapril). On arrival at hospital, the girl was feeling lethargic, with bradycardia, hypotension, and metabolic acidosis. Five hours later, her blood pressure and pulse decreased even further, a complete AV block occurred, and her condition worsened to such a degree that a pacemaker had to be implanted. Thirteen hours later, her heart rate returned to normal and the pacemaker could be removed (Doğan et al. 2011).

We have also recorded another rare case of a 15 -year-old girl who was admitted to hospital following the intoxication by buprenorphine in the form of transdermal therapeutic system. She reportedly received Transtec ${ }^{\circledR} 35 \mu \mathrm{g} / \mathrm{h}$ from her friend and she gradually applied three patches to combat period pain. She took the first at $3 \mathrm{pm}$ and the second one three hours later. From 9:30 pm, she experienced spasms in her limbs, noises in her ears, dry mouth, headache, loss of balance, sickness, weakness, drowsiness, increased heartbeat, and one instance of vomiting. She took a third patch at 9:45 pm. Following this, her friend delivered her to the hospital. The confirmed diagnosis included tachycardia, 
tachypnea, and tremor. She was discharged after two days without further complications.

Our results are consistent with previously published observations. A specific feature of this study is the focus only on intoxications caused by medicinal products. The results also indicate where it is necessary to aim at prevention of such events. Prevention should be focused on the education of parents in order to avoid leaving medicinal products within reach of younger children. Child-resistant packaging and drug take back programs might decrease the risk of unintentional poisonings (White and Kibalama 2017), but according to Lowry et al. (2017) it is still apparent that poison prevention education has not been completely successful in decreasing exposures to toxic drugs. Recently, a study by Wang et al. (2017) stressed the use of medication organizers as a risk factor for unintentional pediatric pharmaceutical ingestions. Furthermore, there is an apparent need for identification and prevention of causes of suicidal attempts, particularly by adolescent girls.

\section{Conclusions}

In our study, drug intoxications were the cause of $0.36 \%$ of all hospital admissions among children and adolescents up to the age of 19 years. Girls accounted for $73 \%$ of cases. The age with the highest occurrence of accidental drug intoxications was between years one and three; $36 \%$ of all children admitted for this reason belonged to this age group. On the other hand, attempted suicides were most frequent among adolescents, mainly girls. We are currently actively dealing with the research, expanding the study cohort and performing further analyses.

\section{Conflict of Interest}

There is no conflict of interest.

\section{Acknowledgements}

Study was supported by an MSMT OPVV project „Toxicology“ (CZ.02.2.69/0.0/0.0/16) and by the Palacký University internal grant IGA_LF_2019_011.

\section{References}

AKIN Y, AĞZIKURU T, CÖMERT S, ATILKAN P, ERDAĞ GC, TELATAR B: Hospitalizations for pediatric intoxication: a study from Istanbul. Turk J Pediatr 53: 369-374, 2011.

ANDIRAN N, SARIKAYALAR F: Pattern of acute poisonings in childhood in Ankara: what has changed in twenty years? Turk J Pediatr 46: 147-152, 2004.

BATES N, EDWARDS N, ROPER J, VOLANS G: Paediatric Toxicology. Handbook of poisoning in children. Macmillan Reference Ltd., London, 1997.

BENTUR Y, OBCHINIKOV ND, CAHANA A, KOVLER N, BLOOM-KRASIK A, LAVON O, GUREVYCH B, LURIE Y: Pediatric poisonings in Israel: National Poison Center data. Isr Med Assoc J 12: 554-559, 2010.

BURGHARDT LC, AYERS JW, BROWNSTEIN JS, BRONSTEIN AC, EWALD MB, BOURGEOIS FT: Adult prescription drug use and pediatric medication exposures and poisonings. Pediatrics 132: 18-27, 2013.

DOĞAN M, BASARANOGLU M, PEKER E, AKBAYRAM S, SAHIN M, UNER A, CAKSEN H: Tarka ${ }^{\circledR}$ overdose in a young child. Hum Exp Toxicol 30: 1392-1398, 2011.

DURAMAZ BB, YILDIRIM HM, KIHTIR HS, YEŞILBAŞ O, ŞEVKETOĞLU E: Evaluation of forensic cases admitted to pediatric intensive care unit. Turk Pediatri Ars 50: 145-150, 2015.

GAITHER JR, LEVENTHAL JM, RYAN SA, CAMENGA DR: National trends in hospitalizations for opioid poisonings among children and adolescents, 1997 to 2012. JAMA Pediatr 170: 1195-1201, 2016.

GAUVIN F, BAILEY B, BRATTON SL: Hospitalizations for pediatric intoxication in Washington State, 1987-1997. Arch Pediatr Adolesc Med 155: 1105-1110, 2001.

GUMMIN DD, MOWRY JB, SPYKER DA, BROOKS DE, OSTERTHALER KM, BANNER W: 2017 Annual Report of the American Association of Poison Control Centers' National Poison Data System (NPDS): 35th Annual Report. Clin Toxicol (Phila) 56: 1213-1415, 2018.

HOY JL, DAY LM, TIBBALLS J, OZANNE-SMITH J: Unintentional poisoning hospitalisations among young children in Victoria. Inj Prev 5: 31-35, 1999.

KIZILYILDIZ BS, KARAMAN K, ÖZEN S, ÜNER A: Acute intoxications among Turkish children. Minerva Pediatr 70: 46-50, 2018. 
LACROIX J, GAUDREAULT P, GAUTHIER M: Admission to a pediatric intensive care unit for poisoning: a review of 105 cases. Crit Care Med 17: 748-750, 1989.

LOWRY JA, BURNS M, CALELLO DP: Pediatric pharmaceutical ingestions. Pediatr Ann 46: 459-465, 2017.

MEYER S, EDDLESTON M, BAILEY B, DESEL H, GOTTSCHLING S, GORTNER L: Unintentional household poisoning in children. Klin Padiatr 219: 254-270, 2007.

MINTEGI S, FERNÁNDEZ A, ALUSTIZA J, CANDUELA V, MONGIL I, CAUBET I, CLERIGUÉ N, HERRANZ M, CRESPO E, FANJUL JL, FERNÁNDEZ P, HUMAYOR J, LANDA J, MUÑOZ JA, LASARTE JR, NÚÑEZ FJ, LÓPEZ J, MOLINA JC, PÉREZ A, POU J, SÁNCHEZ CA, VÁZQUEZ P: Emergency visits for childhood poisoning: a 2-year prospective multicenter survey in Spain. Pediatr Emerg Care 22: 334-338, 2006.

MUND ME, QUARCOO D, GYO C, BRÜGGMANN D, GRONEBERG DA: Paracetamol as a toxic substance for children: aspects of legislation in selected countries. J Occup Med Toxicol 10: 43, 2015.

OUÉDRAOGO M, OUÉDRAOGO M, YÉRÉ S, TRAORÉ S, GUISSOU IP: Acute intoxications in two university hospitals in Burkina Faso. Afr Health Sci 12: 483-486, 2012.

PAWŁOWICZ U, WASILEWSKA A, OLAŃSKI W, STEFANOWICZ M: Epidemiological study of acute poisoning in children: a 5-year retrospective study in the Paediatric University Hospital in Białystok, Poland. Emerg Med J 30: 712-716, 2013.

PEDEN M: World report on child injury prevention. WHO Press, Geneva, 2008, pp 123-137.

RAKOVCOVÁ H: Drug poisoning in children (in Czech). Pediatr praxi 14: 126-129, 2013.

RAKOVCOVÁ H: Poisoning in children (in Czech). Pediatr praxi 14: 55-57, 2013.

SAHIN S, CARMAN KB, DINLEYICI EC: Acute poisoning in children; data of a pediatric emergency unit. Iran J Pediatr 21: 479-484, 2011.

SHOTAR AM: Drug poisoning in childhood. Saudi Med J 26: 1948-1950, 2005.

VON MÜHLENDAHL KE, OBERDISSE U, BUNJES R, BROCKSTEDT M: Vergiftungen im Kindesalter. 4 Auflage. Thieme Verlag, Stuttgart, German, 2003, pp 10-75.

WANG GS, HOPPE JA, BROU L, HEARD KJ: Medication organizers (pill minders) increase the risk for unintentional pediatric ingestions. Clin Toxicol (Phila) 55: 897-901, 2017.

WHITE ND, KIBALAMA W: Prevention of pediatric pharmaceutical poisonings. Am J Lifestyle Med 12: 117-119, 2017.

ZAKHAROV S, NAVRATIL T, PELCLOVA D: Non-fatal suicidal self-poisonings in children and adolescents over a 5-year period (2007-2011). Basic Clin Pharmacol Toxicol 112: 425-430, 2013. 